\title{
Fine structure of the sperm storage tubules in the box turtle oviduct
}

\author{
D. H. Gist and E. N. Fischer \\ Department of Biological Sciences, University of Cincinnati, Cincinnati, OH 25221, USA
}

\begin{abstract}
The sperm storage tubules of the box turtle (Terrapene carolina) were examined by transmission electron microscopy. Tubules containing spermatozoa were surrounded by $6-8$ secretory cells, each of which contains numerous membrane-bound vesicles presumably containing precursors to egg white proteins. The apical membranes of these cells contain microvilli, and the apical lateral membranes possess prominent junctional complexes. Cells comprising the spermatozoa-containing tubules cannot be differentiated from those devoid of spermatozoa. Various quantities of spermatozoa reside free in the lumina of the secretory tubules, and are not in contact with host cells. Only the presence of ducts communicating with the oviduct lumen serve to differentiate the spermatozoa-containing tubules.
\end{abstract}

\section{Introduction}

The storage of spermatozoa in the female reproductive tract is used to extend the period of fertility in most vertebrate groups. It is, however, most extensively used by reptiles and birds (Howarth, 1974), and allows the fertilization of multi-egg clutches, or even multiple clutches, without repeated matings (Gist and Jones, 1989). In most avian and reptilian species, spermatozoa are stored in tubules (SST) located either in the infundibulum or in the uterovaginal regions of the oviduct. The uterovaginal junction appears to be the preferred location in most species (Gist and Jones, 1989), and estimates of 'delayed fertility' for spermatozoa housed there range from several days to several years.

The longevity of stored spermatozoa compared with the relatively short life of most spermatozoa outside the male reproductive tract (Restall, 1967) suggests that the survival of stored spermatozoa might be influenced by the female host. Histochemical studies of uterovaginal sperm storage areas and other regions of the oviduct in birds (Bakst, 1987; Bakst and Bird, 1987) and squamate reptiles (Cuellar, 1966; Kumari et al., 1990) suggest that the SST may possess biochemical adaptations favourable for sperm retention. Close associations between spermatozoa and host cells have been observed in infundibular storage areas (Fox, 1956; Bobr et al., 1964; Bou-Resli et al., 1981). However, neither light nor electron microscope evidence has been obtained that suggests an intimate association between the stored spermatozoa and the cells of the host tubules in the uterovaginal region of the oviduct (Fox, 1963; Cuellar, 1966; Shindler et al., 1967).

In turtles, the sites of sperm storage within the oviduct differ from other groups in that they are located midway between the infundibular and vaginal portions of the oviduct, in the tubules of glands associated with the secretion of egg white (albumen) proteins (Gist and Jones, 1987). Estimates of sperm survival within the tubules of these glands range up to 4 years. In their initial study of the seminal receptacles of the box turtle,

Received 13 April 1992.
Terrapene carolina, Hattan and Gist (1975) found a clear separation between masses of stored spermatozoa and the surrounding secretory epithelium, but hypothesized that it was a procedural artefact. In view of the widespread occurrence of oviductal sperm storage among turtles (Gist and Jones, 1989) and conflicting evidence regarding sperm and host cell interactions, the present study was initiated in the turtle to examine more closely the relationship between stored spermatozoa and the cells that surround them.

\section{Materials and Methods}

Prior examination of a variety of species of temperate zone turtles revealed that the box turtle ( $T$. carolina) possessed the greatest number of stored spermatozoa in the SSTs (Gist and Jones, 1989) and for this reason it was chosen for the present study. Tissue samples were obtained from six oviducts from three adult females captured locally during the summer months.

Turtles were killed by decapitation following Nembutal anaesthesia and the plastron was removed. The oviducts were rapidly removed and immersed in and perfused from the vaginal end with cold $\left(4^{\circ} \mathrm{C}\right)$ glutaraldehyde $(2 \%$ in cacodylate buffer $\left(0.1 \mathrm{~mol} \mathrm{l}^{-1}, \mathrm{pH} 7.4\right)$; ovaries were removed, weighed, and their reproductive status (i.e. preovulatory, postovulatory) noted. Two segments of the oviduct, one from the mid-portion of the albumen region, and the other from the posterior terminus of the albumen region, were selected for further processing and minced into small pieces and stored in fixative overnight in $4^{\circ} \mathrm{C}$. Tissues were then washed twice with the cacodylate buffer, postfixed for $1 \mathrm{~h}$ in a $1: 1$ mixture of $1 \%$ osmium tetroxide and cacodylate buffer $\left(0.1 \mathrm{~mol} \mathrm{l}^{-1}\right)$. After dehydration through a graded ethanol series, the samples were cleared in propylene oxide, embedded in low viscosity resin (Spurr), and sectioned. Thick sections were stained with toluidine blue and examined by light microscopy. Thin sections were cut with a Reichert $\mathrm{Om}$ U3 ultramicrotome, stained with uranyl acetate and $2 \%$ lead citrate, and photographed using either a Zeiss EM 9 S-2 or a Hitachi H-600 transmission electron microscope. 


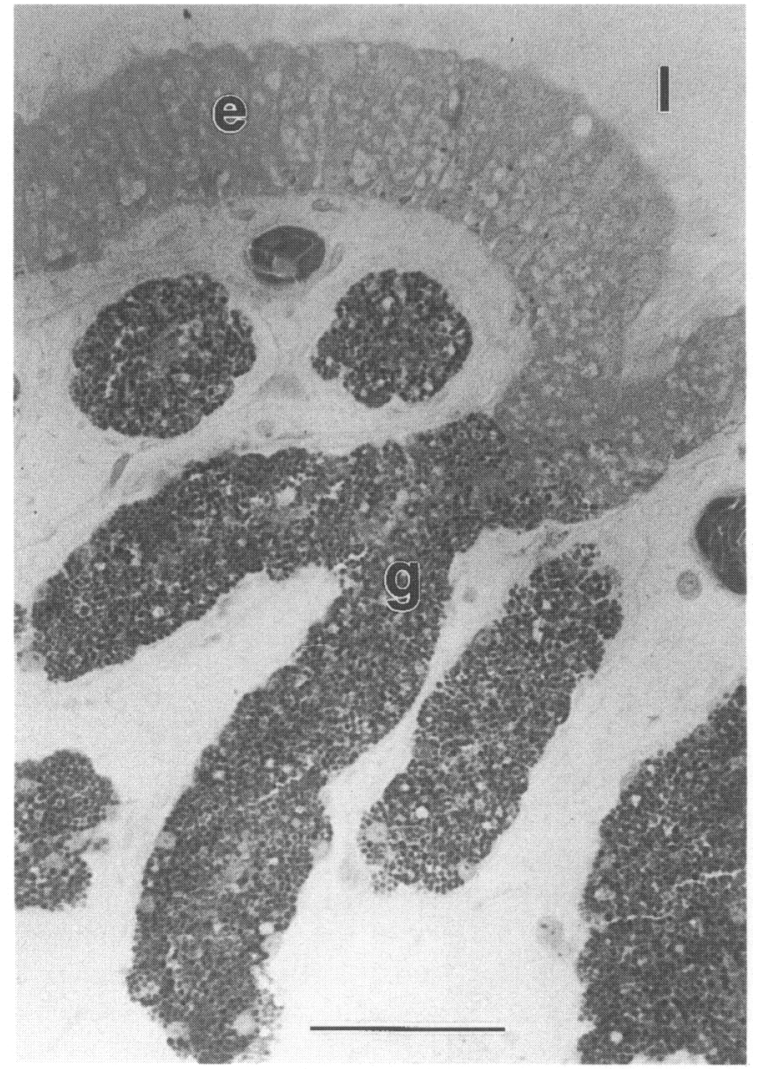

Fig. 1. Thick section through a portion of the oviduct in the caudal terminus of the albumen region of the box turtle. The ciliated pseudostratified epithelium (e) covers the tubular glands ( $\mathrm{g}$ ) which open to the lumen (l) via short epithelial ducts. Bar $=0.05 \mathrm{~mm}$.

\section{Results}

\section{Gross morphology}

The albumen region occupies almost half of the oviduct length and extends from the infundibulum to the uterus; it is separated from the latter by an aglandular transition region (Hattan and Gist, 1975). The albumen glands of the box turtle oviduct are compound tubular and are located in the lamina propria beneath a ciliated pseudostratified columnar epithelium which lines the oviduct lumen (Fig. 1). They communicate with the oviduct lumen via short openings composed of invaginations of the epithelium that communicate abruptly with the glandular epithelium within the lamina propria (Fig. 1). These openings are sparsely distributed throughout most of the albumen region of the oviduct, but become more numerous towards the posterior terminus where they open to the lumen at the base and sides of the longitudinal mucosal folds. It is in this latter location that spermatozoa are stored.

\section{Fine structure}

Tubules in the caudal terminus of the albumen region containing spermatozoa and those devoid of spermatozoa located more anteriorly are similar in structure (Fig. 2). They are

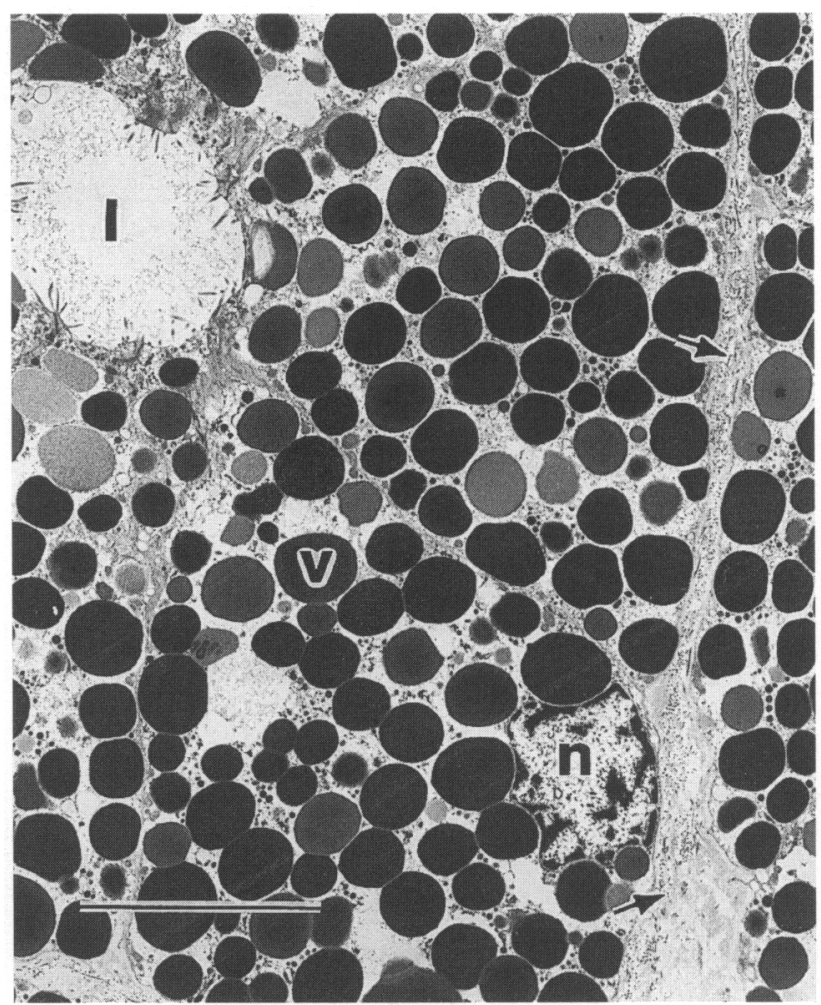

Fig. 2. Cross-section through a portion of a secretory tubule of the box turtle. Cells are filled with secretory vesicles (v) of various electron densities. Connective tissue between tubules (arrows) contains collagen fibres and is devoid of contractile elements. (n) nucleus, (l) lumen of tubule. Bar $=10 \mu \mathrm{m}$.

composed of 6-8 columnar cells with basally located nuclei, and are surrounded by loose connective tissue containing collagen fibres. Myoepithelial cells were not observed. The dominant features of the cells comprising the tubule were the membranebound secretory vesicles $(0.1-4.0 \mu \mathrm{m}$ diameter) of varying electron densities; these completely filled the cytoplasm of the cells. The less opaque of these vesicles tended to be positioned near the apical membrane (Fig. 2) and contained a diffuse flocculent material which resembled that found in the tubule lumen; several such vesicles were seen protruding into the lumen (Fig. 3). Mitochondria were displaced laterally, and, judging from the quantity of secretory vesicles, Golgi vesicles were sparse. The apical surface of the cells formed varying quantities of microvilli which extended into the lumen of the secretory tubule (Fig. 3). In addition to the larger membrane-bound secretory vesicles, the apical cytoplasm contained numerous smaller $(0.2 \mu \mathrm{m})$ vesicles which appeared to be empty (Fig. 3). Some of these vesicles were fused with the apical membrane, and a few could be observed intact in the lumen of the tubule.

A prominent feature of the tubules was the presence of junctional complexes between cells at the apical border (Fig. 4). Immediately beneath these complexes the membranes of adjacent cells were folded together, forming lateral interdigitations (Fig. 4). Desmosomes were concentrated in the apical half of the cells, but were observed all along the lateral membranes of the cells forming the tubules. 


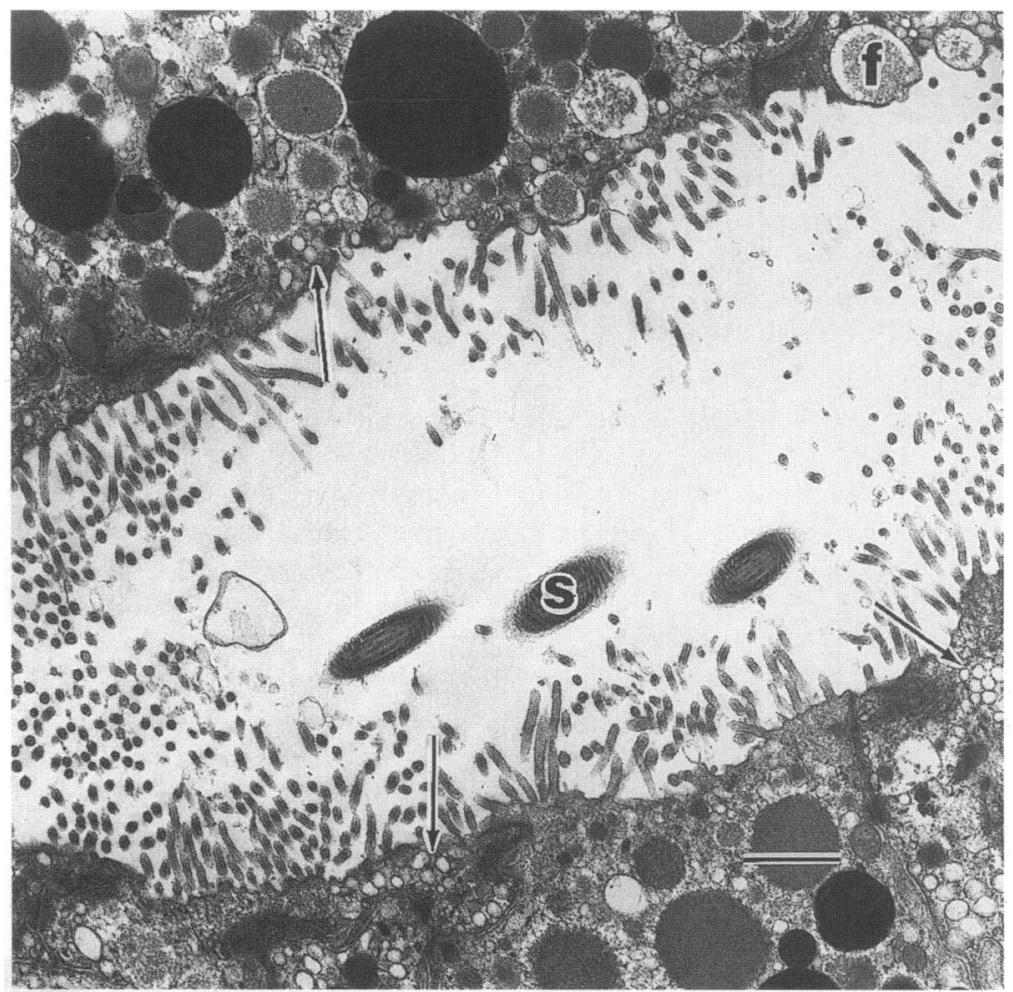

Fig. 3. Apical portion of cells comprising the sperm-containing tubular glands of box turtle. Membrane contains microvilli which extend into tubule lumen. Large vesicles (f) containing flocculent material also protrude into the tubule lumen. Smaller, empty vesicles (arrows) lie immediately beneath the apical membrane. (s) portion of sperm tail. Bar $=0.1 \mu \mathrm{m}$.

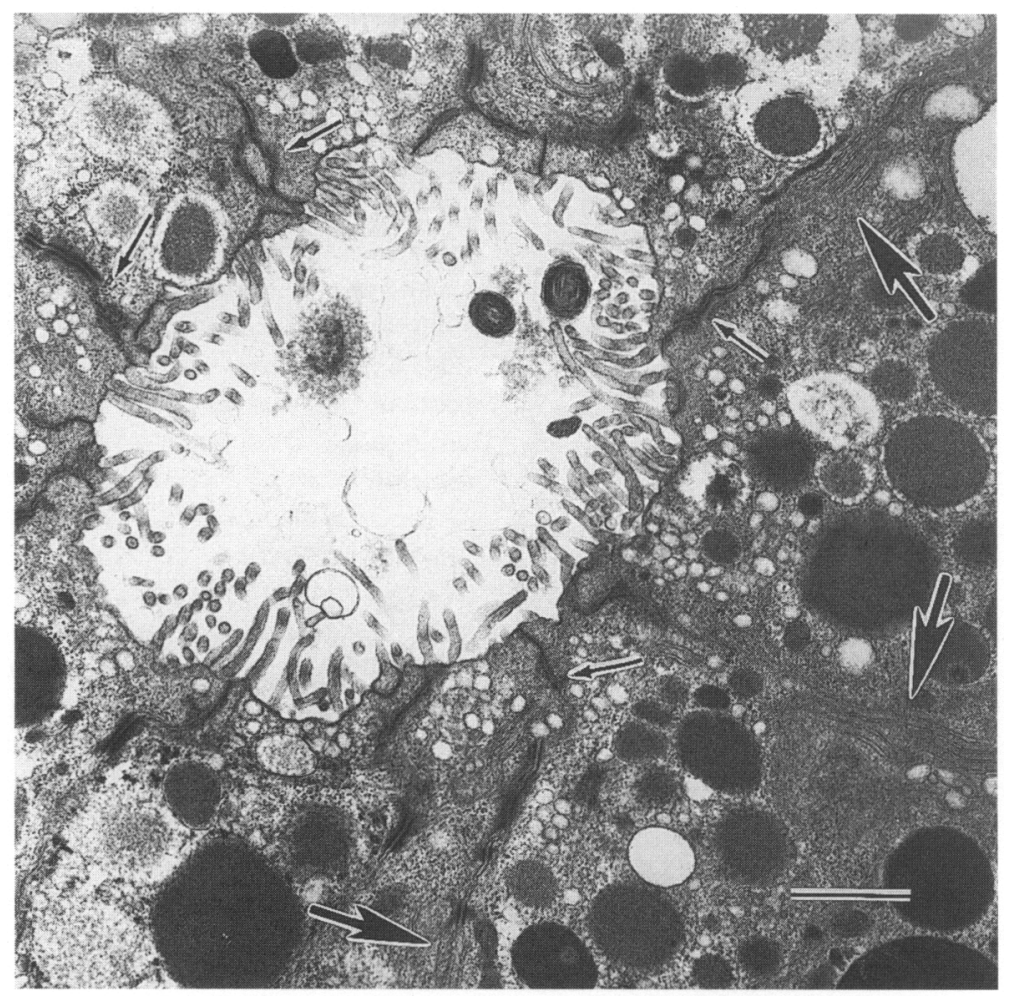

Fig. 4. Cross-section through a secretory tubule of the box turtle illustrating the junctional complexes. Note macula adherens (small arrow), desmosomes (large arrows), and lateral interdigitating membranes. Bar $=0.1 \mu \mathrm{m}$. 


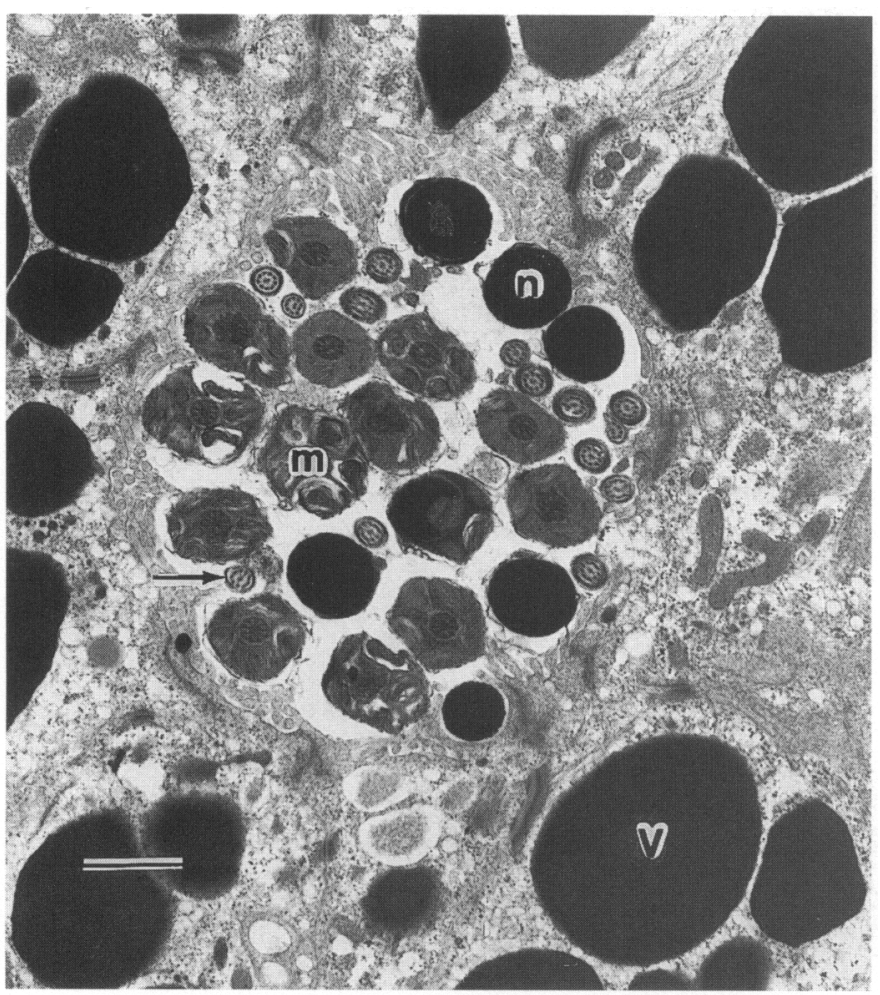

Fig. 5. Cross-section through a box turtle secretory tubule containing stored spermatozoa. Note spermatozoa nuclei $(\mathrm{n})$, midpiece $(\mathrm{m})$, and tail (arrow), and absence of contact between stored spermatozoa and host cells. Bar $=0.1 \mu \mathrm{m}$.

\section{Storage of spermatozoa}

Various quantities of spermatozoa were observed in tubules taken from the caudal albumen region; spermatozoa were not observed in tubules located more anteriorly. Spermatozoa were observed within the lumen of the tubules (Figs 5 and 6), orientated such that the longitudinal axes of the spermatozoa were parallel to the axis of the tubule, with their heads towards the tubule terminus. The spermatozoa were not in contact with the apical surface of the tubular cells, but were loose or packed into the lumen of the tubules. Frequently they were surrounded by flocculent material similar to that found in the apical secretory vesicles (Fig. 6).

\section{Discussion}

The albumen glands of the turtle are named on the basis of their homology to the glands of the avian magnum, which secrete egg white (albumen) proteins, not on the identity of their secretion, which is uncertain. The organization of these glands in the box turtle oviduct is similar to the tubular glands of the avian magnum in that they are highly branched and empty into the lumen via short epithelial ducts usually found at the base of longitudinal mucosal folds or via breaks in the overlying epithelium (Fertuck and Newstead, 1970). Cells forming the secretory tubules in the turtle were filled with membrane-bound vesicles of various sizes and electron densities. These vesicles presumably contain precursors to egg white proteins; cells within the albumen region contain material that reacts with antisera to hen ovalbumin (Gist, unpublished). Analysis of the distribution of the types of secretory granule in the magnum region of hen and quail oviducts (Fertuck and Newstead, 1970; Wyburn et al., 1970) suggests that the electron-dense material within the vesicles represents an immature form of egg white protein, whereas the material contained within the electron transparent vesicles is a mature form of the secretion; these latter vesicles tended to be located close to the apical membrane of the cell. Although we did not examine the box turtle oviduct at different stages of the ovulatory cycle, the electron-translucent vesicles were concentrated in the apical portions of the cell and some protruded into the lumen, while no electron-dense vesicles were observed protruding into the lumen of the tubules. In addition, flocculent material similar to that contained in the apical vesicles was frequently seen in the lumen of the secretory tubules. The apical membranes of the tubular cells possessed microvilli, and, immediately below the apical membrane, numerous small vesicles were observed. The function of these vesicles is unclear; on the basis of the large quantities of the membrane-bound secretory vesicles, these smaller apical vesicles might represent recycled membrane. Alternatively, they may be pinocytotic or even secrete material supporting survival of spermatozoa.

Another similarity between box turtle albumen glands and those of the avian magnum are the prominent junctional complexes between cells forming the secretory tubules. In the box turtle, these included maculae adherens, membrane interdigitations, as well as numerous tight junctions along the length of the lateral membranes. In addition to contributing to the structural integrity of the secretory tubules, which are stretched considerably as ova descend through the albumen region of the oviduct, these junctional complexes in the turtle may constitute an immunological barrier between stored spermatozoa and host, thus facilitating long-term storage.

The cytology of cells forming the secretory tubules in the spermatozoa-containing region of the turtle oviduct was similar in all respects to those in other segments of the albumen region. Only an increased frequency of ducts leading to the oviduct lumen served to distinguish between tubules containing spermatozoa and those without them. Thus, the only structural requirements for storage of spermatozoa within the tubules appears to be access to the oviduct lumen.

Various quantities of spermatozoa were seen within the lumina of the tubular glands. Although some spermatozoa were in contact with the microvilli of the cells forming the tubules, such contacts were sporadic and did not appear to be essential for the presence of spermatozoa within the tubules; this confirms earlier histological observations in this species (Hattan and Gist, 1975) of spermatozoa situated free within the tubule lumen. Among vertebrates, associations of stored spermatozoa with host cells range from casual membrane contacts such as those seen here and in other reptilian (Cuellar, 1966) and avian (Bakst, 1987) groups to actual penetration of spermatozoa heads into the host cells (Hoffman and Wimsatt, 1972; BouResli et al., 1981). The more intimate of these associations between spermatozoa and host cells has prompted speculation that the host cells are necessary to provide nourishment for the stored spermatozoa. This seems unlikely for several reasons. 


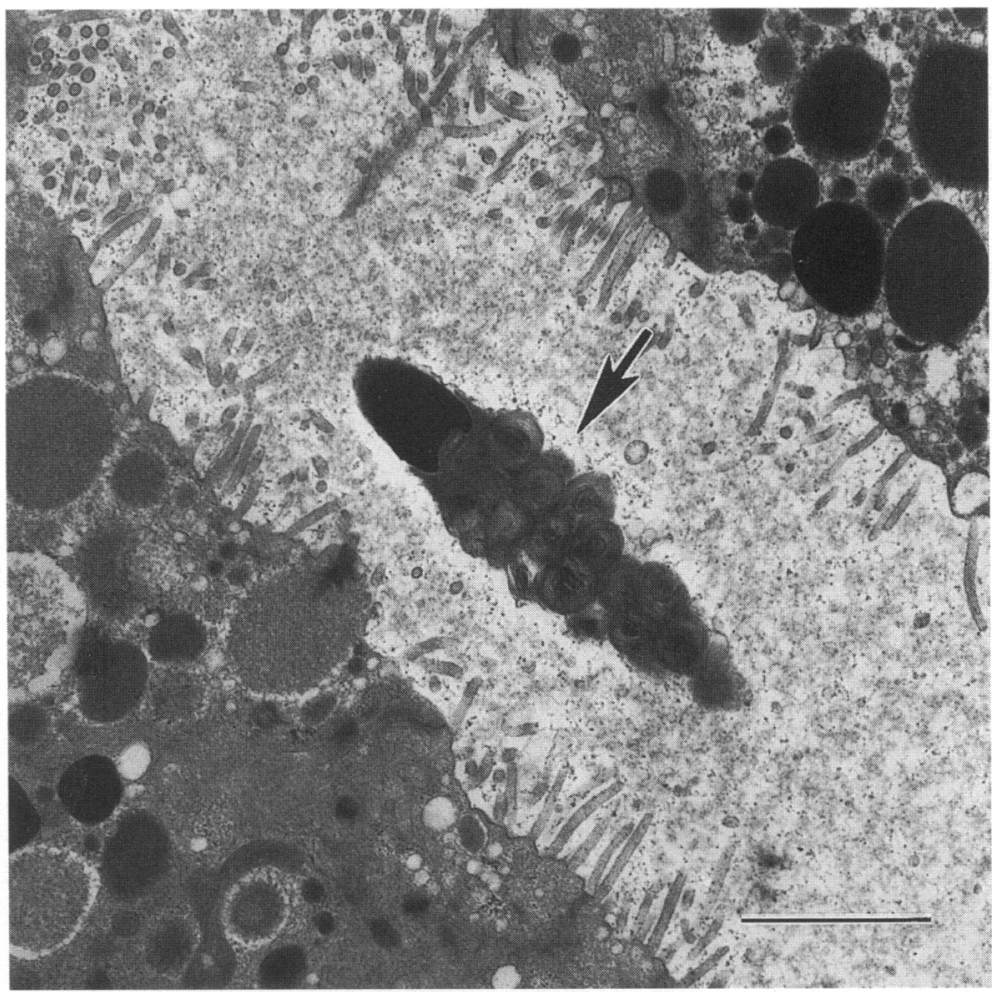

Fig. 6. Longitudinal section through a box turtle tubule containing a solitary spermatozoon. Note flocculent material in the tubule lumen (arrow) which resembles that in the large, apical vesicles. Bar $=2 \mu \mathrm{m}$.

First, spermatozoa are rarely stored singly, but are present in aggregates; thus only the peripheral spermatozoa in an aggregate are in contact with the host cells (Racey, 1979). Second, the more intimate associations between spermatozoa and host cells are found in the infundibular region of the oviduct. In hens (Bobr et al., 1964) and garter snakes (Halpert et al., 1982) the infundibular receptacles are used for temporary spermatozoa storage, and in several squamates infundibular receptacles exhibit evidence (i.e. intracellular vesicles containing fragments of sperm phagocytosis) (Cuellar, 1966; Hoffman and Wimsatt, 1972; Bou-Resli et al., 1981). In contrast, spermatozoa found within the uterovaginal storage area of reptiles and birds, and in the turtle storage tubules, are either aggregated within the tubule lumen or are casually in contact with the apical membrane of the host cells. Thus spermatozoa residing within these latter oviductal storage areas are free from intimate contact with the surrounding cells for long periods. Because of this, any contribution by the host cells towards maintenance of spermatozoa must be secretory in nature, either in the form of a carbohydrate-rich matrix (Halpert et al., 1982; Kumari et al., 1990), or by materials not visualized by microscopy. In turtles, the small vesicles, possibly pinocytotic, seen immediately beneath the apical membranes of host cells might contain material secreted into or absorbed from the lumen to sustain stored spermatozoa; slightly greater numbers of these were observed in cells of spermatozoa-containing tubules, and occasionally the vesicles appeared to be secreted into the lumen. However, the turtles used in these studies were postovulatory, on the basis of the presence of shelled eggs within the oviduct. Thus, the turtles had recently secreted egg white proteins, and the small vesicles may represent recycled membrane.

Sperm storage has been hypothesized to allow spermatozoa inseminated in the autumn to fertilize eggs the following year (Gist et al., 1990) or to allow multi-egg or repeated clutches to be oviposited without benefit of repeated matings (Gist and Jones, 1987, 1989). It is not known how spermatozoa exit the storage tubules to accomplish fertilization. Previous studies of this (Hattan and Gist, 1975) and other (Gist and Jones, 1989) species of turtle have indicated that spermatozoa are orientated within the tubules with their heads towards the blind end of the tubule. This orientation, together with the absence of myoepithelial cells or other means of tubular constriction, suggests that exit of spermatozoa from the glands may be passive. The large, telolecithal eggs of turtles greatly distend the oviduct as they distend, and this distension could displace sperm from the storage tubules. It has been noted that increased numbers of spermatozoa are observed in the lumen of the albumen region of the oviduct in unmated turtles between egg clutches (Gist $e$ t al., 1990), suggesting that ovum descent may dislodge at least some spermatozoa from the storage tubules.

We are grateful to the Department of Pathology, University of Cincinnati College of Medicine, for technical help and for the use of their electron microscope.

\section{References}

Bakst MR (1987) Anatomical basis of sperm storage in the avian oviduct Scanning Microscopy 1 1257-1266 
Bakst MR and Bird DM (1987) Location of oviductal sperm-storage tubules in the American kestrel (Falco sparverius) The Auk 104 321-324

Bobr LW, Lorenz FW and Ogasawara FX (1964) Distribution of spermatozoa in the oviduct and fertility in domestic birds. I. Residence sites of spermatozoa in fowl oviducts journal of Reproduction and Fertility 8 39-47

Bou-Resli MN, Bishay LF and Al-Zaid NS (1981) Observations on the fine structure of the sperm storage crypts in the lizard Acanthodactylus scutellatus hardyi Archives de Biologie 92 287-298

Conner J and Crews D (1980) Sperm transfer and storage in the lizard, Anolis carolinensis Joumal of Morphology 163 331-348

Cuellar $O$ (1966) Oviducal anatomy and sperm storage structures in lizards Joumal of Morphology 119 7-19

Fertuck HC and Newstead JD (1970) Fine structure of the magnum mucosa in quail and hen oviducts Zeitschrift fur Zellforschung und Microscopische Anatomie $103447-459$

Fox W (1956) Seminal receptacles of snakes Anatomical Record 124 $519-539$

Fox W (1963) Special tubules for sperm storage in female lizards Nature 194 500-501

Gist DH and Jones FM (1987) Storage of sperm in the reptilian oviduct Scanning Microscopy 1 1839-1849

Gist DH and Jones JM (1989) Sperm storage within the oviduct of turtles Journal of Morphology 199 379-384

Gist DH, Michaelson JA and Jones JM (1990) Autumn mating in the painted turtle, Chrysemys picta Herpetologica 46 331-336
Halpert AP, Garstka WR and Crews D (1982) Sperm transport and storage and its relation to the annual sexual cycle of the female red-sided garter snake, Thamnophis sirtalis perietalis Journal of Morphology 149 149-159

Hattan LR and Gist DH (1975) Seminal receptacles in the eastern box turtle Terrapene carolina Copeia 1975 505-510

Hoffman LH and Wimsatt WA (1972) Histochemical and electron microscopic observations on the sperm receptacles in the garter snake oviduct American Journal of Anatomy 134 71-90

Howarth BJ (1974) Sperm storage: as a function of the female reproductive tract. In The Oviduct and its Functions pp 227-237 Eds AD Johnson and CW Foley. Academic Press, New York

Kumari TRS, Sarkar HBD and Shivanandappa (1990) Histology and histochemistry of the oviductal sperm storage pockets of the agamid lizard Calotes versicolor Journal of Morphology 203 97-106

Racey PA (1979) The prolonged storage and survival of spermatozoa in Chiroptera Joumal of Reproduction and Fertility 56 391-412

Restall BJ (1967) The biochemical and the physiological relationships between the gametes and the female reproductive tract. In Advances in Reproductive Physiology Vol 2 pp 181-212. Logos Press Ltd, London

Shindler H, Ben-David E and Kempench $\mathbf{O}$ (1967) The relation of spermatozoa to the glandular tissue in the storage sites of the hen oviduct Poultry Science 46 1462-1471

Wyburn GM, Johnston HS, Draper MH and Davidson MF (1970) The fine structure of the infundibulum and magnum of the oviduct of Gallus domesticus Quarterly Journal of Experimental Physiology 55 213-232 